\title{
Amiloidose na cavidade bucal: aspectos clínicos, histopatológicos e ultra-estruturais
}

\section{Amyloidosis in the oral cavity: clinical, histopathological and ultrastructural features}

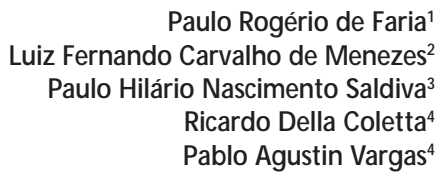

unitermos

Amiloidose

Cavidade bucal

Histopatologia

Ultra-estrutura

\section{resumo}

Amiloidose refere-se à deposição extracelular e progressiva de proteínas fibrilares patogênicas

com características microscópicas e ultra-estruturais similares. A amiloidose pode ser sistêmica

ou localizada. Descrevemos três pacientes que desenvolveram amiloidose intra-oral, sendo

que dois casos manifestaram amiloidose localizada e o outro caso apresentou amiloidose

sistêmica com acometimento de língua. Nos três casos, o exame histopatológico evidenciou

depósitos de amilóide, os quais foram confirmados pela coloração de vermelho-congo. A

ultra-estrutura mostrou material fibrilar compatível com amilóide. Apesar de infreqüente, a

cavidade bucal pode ser um importante local de acometimento de amiloidose.

\section{abstract key words}

Amyloidosis refers to extracellular and progressive deposition of the fibrilar protein with similar microscopic and ultrastructural features. Amyloid deposits can occur in the localized (one organ) or systemic form (several organs). We report three patients which developed intraoral amyloidosis.

Two of them were clinical cases which showed localized amyloidosis and another, an autopsied patient with systemic amyloidosis involving the tongue. In these three cases, the histopathologic study displayed amyloid deposits, which were confirmed with stain Congo red and apple-green birefringence under polarized light. Ultrastructural features presented fibrilar material compatible with amyloid. Although uncommon, oral cavity can be involved by amyloidosis.
Amyloidosis

Oral cavity

Histopathology

Ultrastructure

\section{Introdução}

Amiloidose é um termo que se refere à deposição extracelular, progressiva e irreversível de um grupo heterogêneo de proteínas fibrilares patogênicas que apresentam características microscópicas e ultra-estruturais similares $(2,25)$. Os depósitos de amilóide podem ser localizados ou sistêmicos $(18,20)$. Na região de cabeça e pescoço a amiloidose é incomum, sendo os sítios mais acometidos a laringe, a faringe e a cavidade bucal. Na boca, a língua é o sítio mais afetado ( $12 \%$ a $26 \%$ dos casos) e macroglossia é o sinal clínico mais comum, ocorrendo em $25 \%$ dos casos $(9,12$, $16,23)$.

Microscopicamente o amilóide apresenta-se amorfo, acelular, hialino, eosinofílico e homogêneo. Na coloração de vermelho-congo, o amilóide mostra birrefringência verde-maçã sob luz polarizada (3, 7,2 4). Ultra-estruturalmente, as fibrilas apresentam-se rígidas e não-ramificadas, podendo estar dispostas isoladamente ou em feixes. O diâmetro das fibrilas varia de $8 \mathrm{~nm}$ a $15 \mathrm{~nm}(8,19,21,25)$.
1. Mestre em Estomatopatologia pela Faculdade de Odontologia de Piracicaba da Universidade Estadual de Campinas (Unicamp). 2. Médico patologista da Faculdade de Medicina da Universidade de São Paulo (USP) 3. Professor titular de Patologia da Faculdade de Medicina da USP. 4. Professor da disciplina de Patologia da Faculdade de Odontologia de Piracicaba da Unicamp.

Agências financiadoras: Capes, Fapesp, CNPq. 
Neste trabalho relatamos dois casos clínicos de amiloidose em cavidade bucal diagnosticados no Orocentro da Faculdade de Odontologia de Piracicaba da Unicamp e um caso de amiloidose sistêmica acometendo um paciente autopsiado no Serviço de Verificação de Óbitos da Capital da Faculdade de Medicina da Universidade de São Paulo. Além disso, discutimos os aspectos clínicos, histopatológicos e ultra-estruturais da amiloidose bucal.

\section{Relato dos casos}

Todos os casos foram submetidos a exame histopatológico. As amostras das biópsias e da autópsia foram fixadas em formol tamponado a $10 \%$. Foram realizadas colorações de H/E e vermelho-congo. No caso 3, um fragmento de língua de $1 \mathrm{~mm}^{2}$ foi fixado em glutaraldeído a $2 \%$ para estudo ultra-estrutural em microscópio eletrônico de transmissão (Zeiss-EM10).

\section{Caso 1}

Paciente do sexo feminino, 33 anos de idade, procurou o Orocentro da Faculdade de Odontologia de Piracicaba da Unicamp em agosto de 1993 relatando aumento de volume em língua há um ano. A história médica não revelou nenhuma doença sistêmica. No exame clínico intra-oral, notou-se lesão nodular em dorso de língua com $0,8 \mathrm{~cm}$ de diâmetro e ulcerada. Realizou-se biópsia excisional, a qual foi encaminhada para exame histopatológico. A microscopia ótica (MO) mostrou epitélio estratificado pavimentoso paraqueratinizado e tecido conjuntivo fibroso contendo depósitos extracelulares de material hialino localizados subjacentes ao epitélio e em algumas áreas substituindo as fibras musculares esqueléticas. Podem-se evidenciar também depósitos perivasculares. Sob luz polarizada o material apresentou birrefringência verde-maçã, permitindo a realização do diagnóstico de amiloidose primária de língua. A paciente não apresentou recidiva da lesão após nove anos de acompanhamento clínico.

\section{Caso 2}

Paciente do sexo masculino, 64 anos de idade, procurou atendimento no Orocentro em agosto de 1992 relatando aumento de volume em lábio inferior e assoalho bucal há seis meses. A história médica mostrou diagnóstico de mieloma múltiplo (MM) quatro meses antes de procurar nosso atendimento. O diagnóstico de MM foi confirmado por punção aspirativa de osso ilíaco. Desde então o paciente foi submetido a tratamento hematológico. $\mathrm{Na}$ eletroforese de proteínas séricas observou-se presença de pequena quantidade de componente monoclonal na região gamaglobulínica. A urina foi positiva para proteína Bence-Jones. O exame extra-oral revelou aumento de volume do lábio inferior fazendo protuberância de $0,5 \mathrm{~cm}$. Intra-oralmente, notaram-se, entre o assoalho bucal e o ventre da língua, nódulos de $0,5 \mathrm{~cm}$ de diâmetro e, na mucosa labial, de $2 \mathrm{~cm}$ de diâmetro e endurecido (Figura 1). Devido à história de MM, uma hipótese de amiloidose foi aventada. Realizaram-se então biópsia incisional de nódulo lingual e exame histopatológico. A MO mostrou fragmento revestido de epitélio estratificado pavimentoso hiperparaqueratinizado e depósito de material amorfo disposto difusamente em todo o tecido conjuntivo, com áreas focais de infiltrado inflamatório crônico (Figura 2). Sob luz polarizada, o material apresentou birrefringência verde-maçã (Figura 3), levando ao diagnóstico de amiloidose lingual. Em 1996, o paciente retornou devido a aumento de volume em língua, que foi diagnosticado como macroglossia difusa (Figura 4). No mesmo ano o paciente faleceu em decorrência do MM.

\section{Caso 3}

Paciente do sexo masculino, 44 anos de idade, com diagnóstico de amiloidose primária, síndrome nefrótica e síndrome de Addison, deu entrada no pronto-socorro do Hospital das Clínicas da Faculdade de Medicina da USP em março de 2000 em estado de choque e derrame pleural à esquerda. No período de internação, o paciente evoluiu com parada cardiorrespiratória e fibrilação ventricular, indo a óbito. Na autópsia, evidenciaram-se ascite, derrame pleural e pericárdico à esquerda. Nódulos amarelados dis-

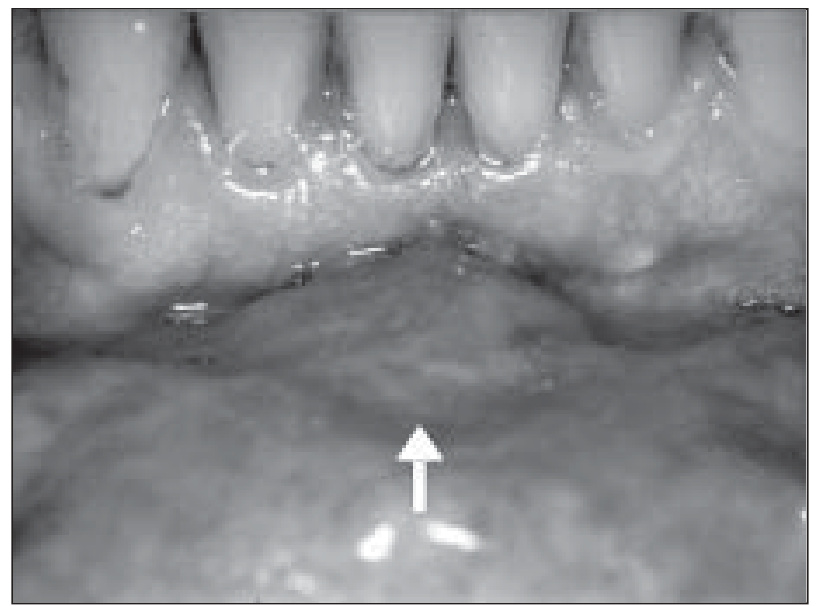

Figura 1 - Caso 2. Aspecto clínico da amiloidose bucal mostrando aumento de volume em mucosa vestibular anterior (seta branca, região de incisivos inferiores) 


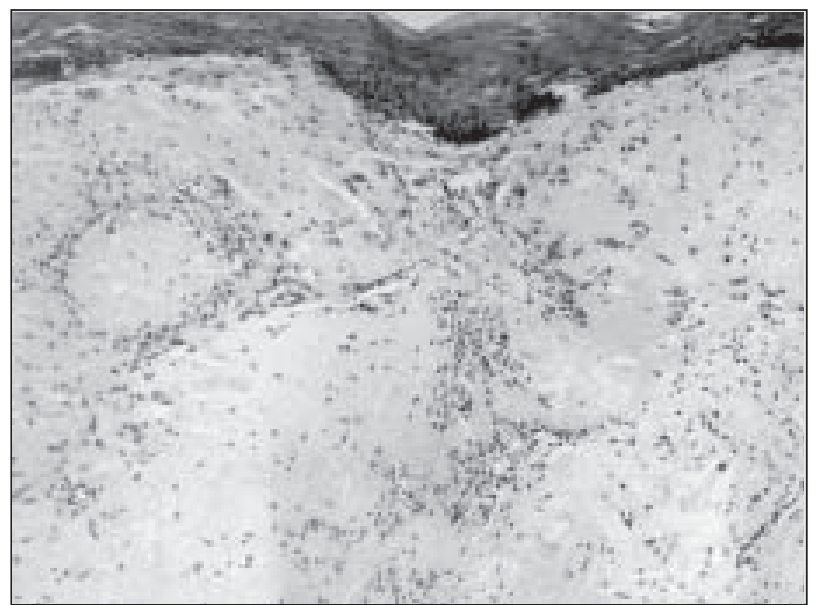

Figura 2 - Caso 2. Microscopia de nódulo de ventre de língua. Presença de material amorfo distribuído difusamente no tecido conjuntivo com áreas de infiltrado inflamatório crônico (vermelho-congo, aumento original de 100x)

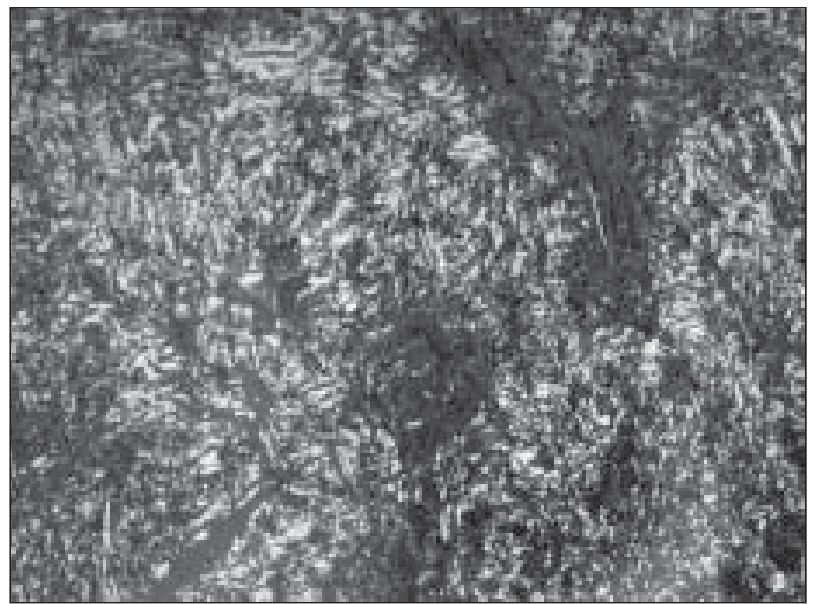

Figura 3 - Caso 2. Aspecto microscópico do amilóide sob luz polarizada exibindo birrefringência verde-maçã (vermelho-congo, aumento original de 100x)

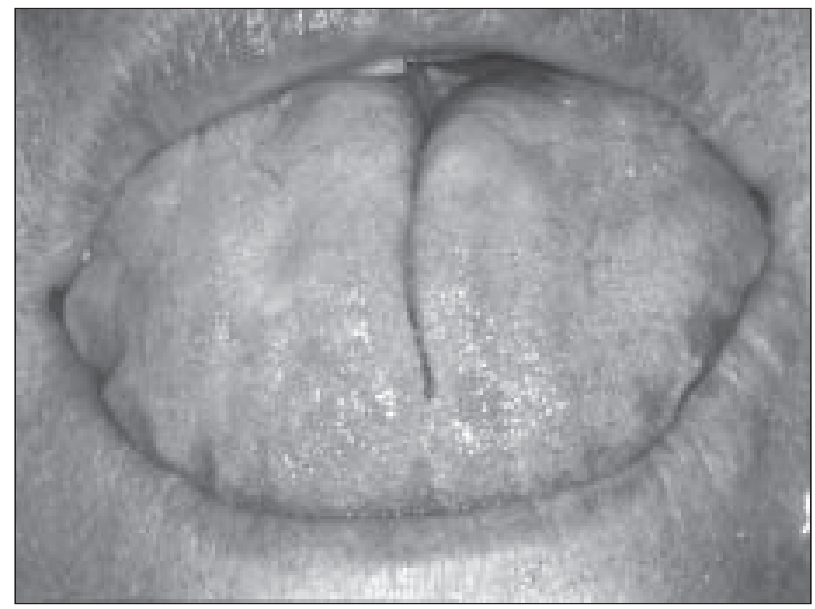

Figura 4 - Caso 2. Aumento de volume da língua. Nota-se a presença de impressões das superfícies dentais em borda lateral da língua

seminados foram observados em fígado, rins, baço, adrenais, coração, músculo esquelético, tireóide, estômago e cólon, os quais foram compatíveis com amiloidose. A língua apresentou-se amarelada, com consistência borrachóide, aumentada de tamanho, despapilada e com indentação em bordas laterais. A MO mostrou tecido epitelial estratificado pavimentoso paraqueratinizado e tecido conjuntivo fibroso contendo depósitos de material amorfo e eosinofílico distribuídos difusamente. Havia envolvimento de parede de vasos sangüíneos pelos depósitos. Sob luz polarizada, notamos birrefringência verdemaçã compatível com amilóide. Na microscopia eletrônica de transmissão observou-se material fibrilar e amorfo envolvendo fibroblastos degenerados (Figura 5). Em maior aumento, o material mostrava estruturas filamentares, retas ou levemente curvadas, não-ramificadas e dispostas em arranjo desordenado.

\section{Discussão}

Amiloidose representa um grupo de doenças que partilham a deposição de proteínas fibrilares e insolúveis com características morfológicas e estruturais semelhantes (18, 25). Afeta principalmente indivíduos entre a quarta e oitava décadas de vida. A razão homem/mulher é de 3:1 (16). Em nossos três casos, a média de idade foi de 46 anos e a razão homem/mulher foi de 2:1. De acordo com a Tabela, que representa a revisão de literatura de $41 \mathrm{ca}$ sos de amiloidose bucal, os homens foram mais afetados do que as mulheres (75,5\% vs. $24,4 \%$ ). A razão homem/ mulher e a média de idade foram de 3,3:1 e 62,94 $\pm 7,71$ anos, respectivamente.

A região de cabeça e pescoço pode ser acometida por amiloidose, sendo a forma localizada a mais prevalente $(3,10,16)$. Laringe, faringe e cavidade bucal são os locais mais envolvidos (16). Na boca, os depósitos de amilóide

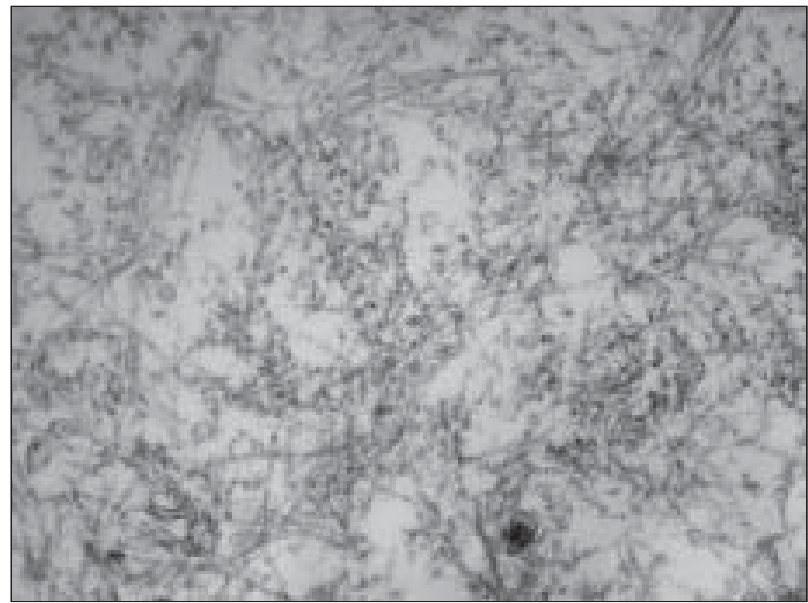

Figura 5 - Caso 3. Fibroblastos degenerados, ricos em retículo endoplasmático liso e rugoso e envoltos por abundante matriz de amilóide (microscopia eletrônica de transmissão, aumento original de $2.500 x$ ) 


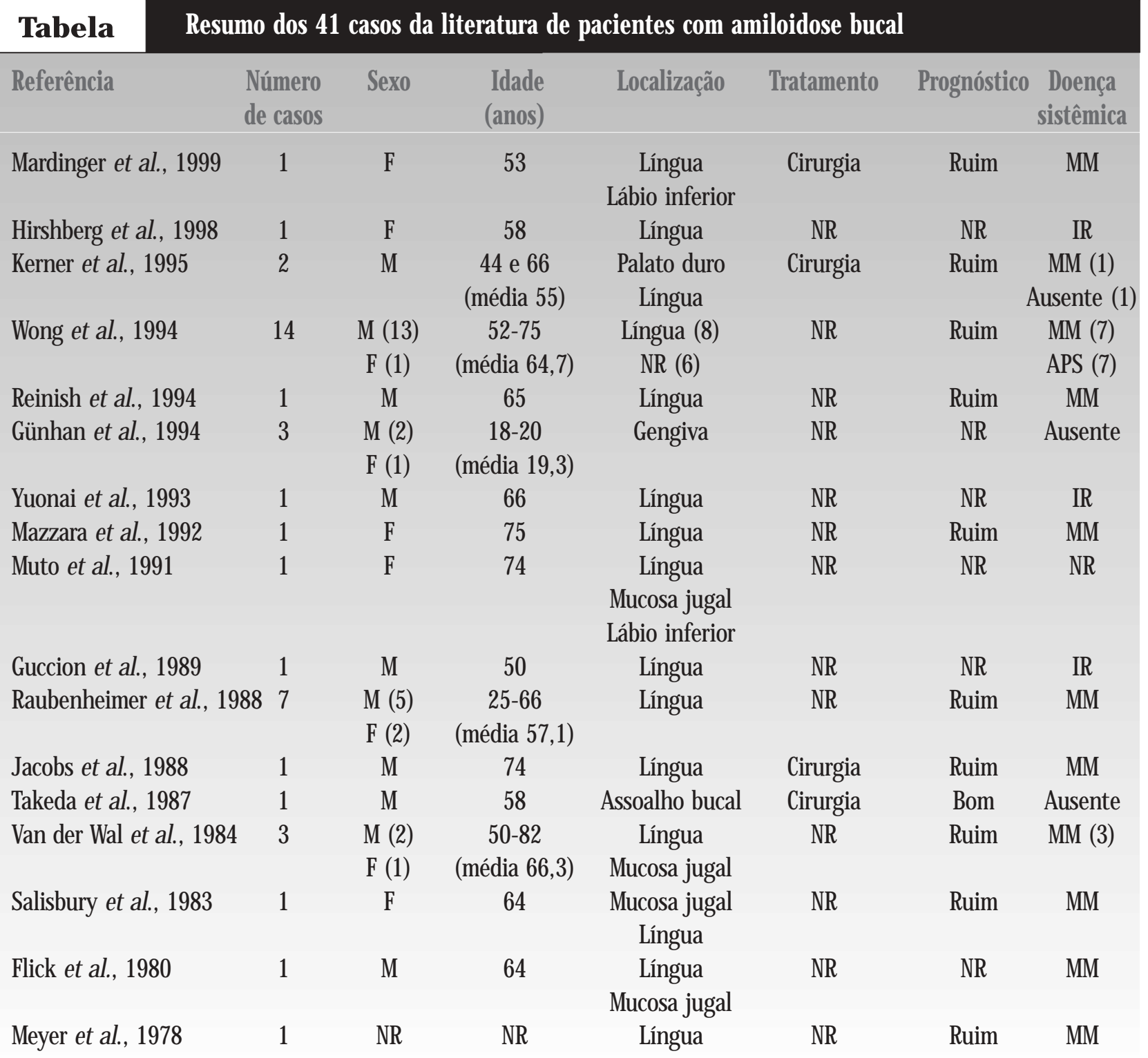

$M=$ masculino; $F$ = feminino; $N R$ = não-relatado; $I R$ = insuficiência renal; $M M$ = mieloma múltiplo; $A P S=$ amiloidose primária sistêmica.

ocorrem em forma de pápulas, nódulos, placas e macroglossia (18), podendo ser o primeiro sintoma de amiloidose sistêmica (4). A macroglossia ocorre em 12\% a $26 \%$ dos casos $(6,9,13)$, e a língua mostra-se firme, endurecida, fissurada ou ulcerada, hemorrágica, dolori$\mathrm{da}$, com ou sem indentação em borda lateral. A coloração varia de amarelada a avermelhada $(15,20)$. Outros sítios envolvidos foram glândula salivar $(5,4 \%)$, mucosa jugal $(3,64 \%)$, gengiva $(1,84 \%)$ e lábio $(1,84 \%)(12,18)$. Dos 41 casos revisados (Tabela), a língua (72\%) foi o local mais afetado, seguido por mucosa jugal $(12,5 \%)$ e lábio inferior (6,25\%).

Após a realização do diagnóstico de amiloidose bucal, deve-se proceder a uma investigação clínica detalhada do paciente para descartar a possibilidade de doença subja- cente e depósitos sistêmicos. Além disso, nos casos de macroglossia, pode-se fazer redução cirúrgica do órgão ou acompanhamento clínico, na dependência de a macroglossia estar provocando dificuldades respiratórias e de alimentação $(9,18)$. Por outro lado, nos casos de depósitos localizados, estão indicados biópsia excisional e acompanhamento do paciente devido a uma possível recidiva (16).

A confirmação de depósito sistêmico de amilóide pode ser realizada a partir de amostras teciduais obtidas de vários órgãos, inclusive da cavidade bucal, mesmo na ausência clínica de lesões $(17,19,24)$. De acordo com Wong et al. (24), nestes casos, os principais locais para a realização de biópsia na cavidade bucal são a gengiva e a língua. Semelhante a isso, Raubenheimer et al. (17) sugeriram que 
se deva fazer como rotina biópsia de língua em pacientes com MM que ainda não desenvolveram amiloidose, como forma de descobrir precocemente o depósito deste material nos tecidos. No entanto, segundo Nandapalan et al. (16), apenas $60 \%$ dos casos de amiloidose sistêmica apresentaram depósitos de amilóide nas línguas biopsiadas.

O diagnóstico diferencial de macroglossia inclui doenças infiltrativas (tuberculose e linfoma) e neurofibroma difuso $(13,20)$. Nas lesões nodulares, doenças neurais (tumor de células granulares, schwannoma e neuroma) são os principais diferenciais. Nos quadros difusos, neurofibromas como parte da neurofibromatose e processos sistêmicos generalizados devem ser considerados (20).

A forma localizada da doença apresenta prognóstico mais favorável do que a sistêmica (3). O tratamento consiste em remoção cirúrgica com baixo índice de recidiva $(3,10)$. Pela Tabela, $53,7 \%$ dos pacientes tinham doença sistêmica e todos apresentaram prognóstico ruim. $\mathrm{O}$ tratamento cirúrgico foi realizado em apenas quatro casos. Em três deles havia doença sistêmica. Em 38 casos não havia relato de qualquer tipo de tratamento. A cirurgia não foi realizada devido às condições precárias de saúde em um caso. Sangramento excessivo pode ocorrer devido à perda da integridade vascular provocada pela infiltração do amilóide na parede dos vasos. O uso de esteróides sistêmicos ou locais e radioterapia não têm mostrado resultados promissores (16).

No caso 1, a amiloidose envolvia apenas a língua. Não havia presença de doença subjacente e depósitos sistêmi- cos. Na literatura há poucos relatos de amiloidose localizada em cavidade bucal $(21,22)$. A etiopatogenia destes casos é desconhecida (22), o tratamento de escolha é a remoção cirúrgica e a recidiva é rara.

Em pacientes com MM o prognóstico é desfavorável, com deterioração rápida e sobrevida de alguns meses (3, 13, 20, 23). Insuficiência cardíaca e renal são as principais complicações observadas $(17,20)$. Na série relatada por Wong et al. (24), a média de sobrevida foi de oito meses, porém há relatos de sobrevida de até 24,5 meses (5). No caso 2, o paciente desenvolveu MM e amiloidose, apresentando sobrevida de 46 meses, provavelmente por não apresentar comprometimento sistêmico por amilóide.

Ultra-estruturalmente, o amilóide é composto de fibrilas dispostas isoladamente ou em feixes, não-ramificadas e com arranjo desordenado. O diâmetro varia de $8 \mathrm{~nm}$ a $15 \mathrm{~nm}(8,21,25)$. A análise ultra-estrutural da língua (caso 3) confirmou a natureza fibrilar do amilóide, mostrando arranjo desordenado e filamentos retos ou levemente curvados. Devido à diversidade das proteínas fibrilares do amilóide e a sua ligação com doenças e síndromes subjacentes, métodos de imunoistoquímica são aplicados para catalogar as diferentes classes de amilóide e determinar quadros patológicos subjacentes $(11,17,19)$.

Em resumo, descrevemos três casos de amiloidose bucal enfatizando seus aspectos clínicos, histopatológicos e ultra-estruturais. Amiloidose é incomum na cavidade bucal, afeta predominantemente a língua e, quando associada ao MM, pode ser uma manifestação inicial da doença.

\section{Referências}

1. Al-Hashimi, I. et al. 0 ral amyloidosis: two unusual case presentations. Oral Surg. Oral M ed. Oral Pathol., 63:586-91, 1987.

2.C levens, R.A et al.. Multifocal amylo idosis of the pediatric airway. Arch Otolaryngol Head Neck Surg., 121:229-32, 1995.

3. Cohen,A.S.\& Connors, L.H.The pathogenesis and bio chemistry of amyloido sis. J. Pathol., 151: 1-10, 1987.

4. Flick,W .G . \& Lawrence, F.R. 0 ral amyloidosis as initial symptom of multiple myeloma. Oral Surg. Oral Med. Oral Pathol., 49: 18-20, 1980.

5. Gertz, M.A. et al. A myloidosis. Hematol. Oncol. Clin. N orth Am., 13: 1211-33, 1999.

6. Guccion, J.G. et al. Hemodialysis-associated amyloidosis presenting as lingual nodules. Oral Surg. Oral M ed. Oral Pathol., 68: 618-23, 1989.

7. Günhan, Ö. et al. Generalized gingival enlargement due to accumulation of amyloid-like material. J. Oral Pathol. Med., 23: 423-8, 1994.
8. Hirshberg, A. et al. $\beta$-2-microglobulin-associated nodular amylo idosis of the tongue. Int. J. Oral Maxillofac. Surg., 27: 226-8, 1998.

9. Jaco bs, P. et al. Massive macroglossia, amylo idosis and myeloma. Postgrad. M ed. J., 64:696-8, 1988.

10. Kerner, M.M. et al. A myloidosis of the head and neck: a clinicopathologic study of the UCLA experience, 19551991. Arch. Otolaryngol. Head N eck Surg., 121:778-82, 1995

11. Linke, R.P. et al. Immuno-electron microscopic identification and classification of amyloid in tissue sections by the postembedding protein-A gold method. Ultrastruct. Pathol. 4:1-7, 1983.

12. $M$ ardinger, 0 . et al. Surgical management of macroglossia due to primary amyloidosis. Int. J. Oral M axillofac. Surg., 28:12931, 1999.

13. Mazzara, C .A . et al.C linical and patholo gic diagnosis pathologic quiz case 2. Arch. Otolaryngol. Head Neck Surg., 118: 440, discussion 443, 1992. 
14. M eyer, I. et al.A mylo idosis of the tongue secondary to multiple myeloma. J. Oral Surg., 36: 459-61, 1978.

15. Muto,T. et al. Multiple nodules of the lip, cheeks, and tongue.J. Oral Maxillofac. Surg., 49: 1003-6, 1991.

16. $\mathrm{N}$ andapalan,V.et al. Localized amylo idosis of the parotid gland: a case report and review of the localized amyloidosis of the head and neck. Head N eck, 20: 73-8, 1998.

17. Raubenheimer, E.J. et al. Multiple myeloma and amyloidosis of the tongue. J. Oral Pathol. Med., 17: 554-9, 1988.

18. Reinish, E.l. et al. Tongue, primary amyloidosis, and multiple myeloma. Oral Surg. Oral M ed. Oral Pathol., 77: 121-5, 1994.

19. Röcken, $C$. et al. The classification of amyloidosis deposits in clinicopathological practice. Histopathology, 29: 325-35, 1996.
20. Salisbury, P.L. et al. O ral amylo idosis: a late complication of multiple myeloma. Oral Surg. Oral Med. Oral Pathol., 56: 4850, 1993.

21.Takeda,Y. et al. Localized oral amyloidosis: ultrastructural and immunohistochemical study. J. Oral Pathol. Med., 16: 27881, 1987.

22. Timosca, G . et al. Primary localized amyloidosis of the palate. Oral Surg. Oral Med. Oral Pathol., 44: 77-83, 1977.

23. van der $W$ all, $N$. et al. A myloido sis of the tongue: a clinical and postmortem study. J. Oral Pathol., 13:632-9, 1984.

24. W ong, C.K. \& W ang, W J. Systemic amyloidosis. Dermatology, 189: 47-51, 1994.

25.Yuonai, F. \& Sciubba,J.J. N odular amylo ido sis. J. Oral Pathol. M ed., 22: 231-4, 1993. 